\title{
Modulation in Plant Growth and Drought Tolerance of Wheat Crop upon Inoculation of Drought-tolerant- Bacillus Species Isolated from Hot Arid Soil of India
}

\author{
Vinod Kumar Yadav ${ }^{1,2}$, Neeta Bhagat ${ }^{2 *}$ and Sushil K. Sharma ${ }^{1,3 *}$ (D) \\ ${ }^{1}$ ICAR-National Bureau of Agriculturally Important Microorganisms (ICAR-NBAIM), Kushmaur, \\ Maunath Bhanjan - 275 103, Uttar Pradesh, India. \\ ${ }^{2}$ Amity Institute of Biotechnology, Amity University Uttar Pradesh, Noida - 201 313, India. \\ ${ }^{3}$ ICAR-National Institute of Biotic Stress Management, Baronda, Raipur - 493 225, Chhattisgarh, India.
}

\begin{abstract}
Drought is one of the most detrimental environmental stressors to plants with the potential to decrease crop yields and affect agricultural sustainability. Native bacteria with beneficial traits enhance plant growth and help avoid and reverse the effects of drought in plants to a greater extent. In the present study, we aimed to (i) isolate drought tolerant Bacillus isolates from the rhizosphere soil of wheat crop grown at different locations in Jaisalmer district, Rajasthan state and (ii) further evaluate their ability to enhance plant growth and induce drought tolerance in wheat ( Var. HD-2967) grown under drought stress conditions. Of more than $\mathbf{1 0 0}$ isolates, two putative Bacillus isolates capable of tolerating $\mathbf{3 0}$ \% polyethylene glycol-6000 (PEG-6000) [equivalent to $-9.80 \mathrm{MPa}$ (Megapascal)] were identified as Bacillus altitudinis DT-89 and Bacillus paramycoides DT-113. These isolates exhibited different plant growth promoting (PGP) attributes such as phosphate solubilization, and production of siderophore, exopolysaccharide, ammonia, indole acetic acid and cytokinin at low osmotic stress of 10\% PEG-6000 but shown variable response at higher osmotic stress particularly at 30\% PEG-6000. However, they did not show any antifungal activity and one isolate was negative for phosphate solubilization. Of two strains, B. altitudinis DT-89 function more prominently with respect to plant growth promotion and drought tolerance to plant in the early stage but protective traits of $B$. paramycoides DT-113 was more prominent after 75 days as evident by increased EPS (164\%), root dry weight (144.44\%), chlorophyll content $(90.26 \%)$, SOD (389\%) and proline (99.3\%). The results support both the strains as a potential candidate to alleviate drought stress and enhance plant growth in the drought regions.
\end{abstract}

Keywords: Plant growth promoting bacteria, Bacillus, EPS, Siderophore, IAA, GA

*Correspondence: nbhagat@amity.edu; sks_micro@rediffmail.com

(Received: October 13, 2021; accepted: December 9, 2021)

Citation: Yadav VK, Bhagat N, Sharma SK. Modulation in Plant Growth and Drought Tolerance of Wheat Crop upon Inoculation of Drought-tolerant-Bacillus Species Isolated from Hot Arid Soil of India. J Pure Appl Microbiol. 2022;16(1):246-262. doi: 10.22207/JPAM.16.1.14

C The Author(s) 2022. Open Access. This article is distributed under the terms of the Creative Commons Attribution 4.0 International License which permits unrestricted use, sharing, distribution, and reproduction in any medium, provided you give appropriate credit to the original author(s) and the source, provide a link to the Creative Commons license, and indicate if changes were made. 


\section{INTRODUCTION}

Drought, as a consequence of climate change, is one of the major threats to agricultural sustainability and has the potential to tremendously reduce crop yields all over the world. This is especially true for tropical countries where drought is the single most important contributor to crop yield reduction. ${ }^{1}$ Growth and yield reduction in crops such as maize, barley, wheat and rice are a matter of concern as it can potentially lead to global food scarcity. ${ }^{2}$ Water deficit conditions negatively affects seed germination and seed development, fresh weight of the plants, membrane stability index. ${ }^{3}$ Furthermore, drought causes decreased diffusion of water-soluble nutrients such as calcium, magnesium, silica, nitrate, and sulphate from the soil. ${ }^{4}$ This, in turn, affects metabolic and physiological activities in the plants like carbon dioxide assimilation, stomatal closure, photosynthesis, proline metabolism, nitrogen metabolism, antioxidant defense system, and plant-water relations. ${ }^{5}$

Millions of microorganisms are dwelling in the soil and also form mutualistic associations with plant roots forming complex ecological communities that assist plant growth and development. In the presence of biotic and abiotic stressors, changes in these ecological communities take place that helps enhance tolerance of the plants to environmental stressors. ${ }^{6}$ In order to mitigate drought stress, one promising mechanism is the use of plant growth promoting bacteria (PGPB) that imparts drought-tolerance properties to plants. ${ }^{7}$ Under drought stress conditions, PGPB encourage root growth by bringing about changes to root architecture which enables enhanced water uptake by the plant. It has also been seen that inoculation of PGPB can enhance shoot growth under the influence of several plant growth mechanisms of microbes. ${ }^{8}$ A study has shown that the treatment of maize plants with PGPB induce closure of stomata to conserve water during drought conditions. ${ }^{9}$ Other study has shown increased cellular osmolytes of plants for stress tolerance under drought upon PGPB inoculation. ${ }^{10}$ One of the characteristic features of drought-stressed plants is the accumulation of free radicals that cause damage to the cellular machinery of plants. PGPB inoculation leads to the production of antioxidants such as peroxidase and catalase that eliminates free radicals and protects plant cells from damage. ${ }^{11}$ This phenomenon has been specifically demonstrated in lettuce plants upon inoculation with Pseudomonas sp. and Glomus sp. ${ }^{10,12}$ Other mechanisms that lead to the improvement of crop yield and root biomass include phytohormone production, ACC deaminase production, production of exopolysaccharides, and solubilization of phosphate and EPS production that helps the plant in water and nutrient acquisition from the soil. ${ }^{12,13}$

Apart from the above, PGPB has been instrumental in plants growth as best studied in desert regions where the climate is mainly hot and dry throughout the year. Plants that grow in these regions acquire drought resistance from phytohormones such as IAA, cytokinin, and abscisic acid (ABA) produced by PGPB in the soil. ${ }^{6}$ As a result, PGPB are often used for desert farming specifically for phytostimulation, biofertilization, and biocontrol processes. ${ }^{14}$ The PGP activities of these bacteria have been shown to be more pronounced in the areas that have long dry periods as compared to areas where drought occurs less frequently. ${ }^{15}$ Comparative studies have shown that plants inoculated with PGPB had higher chlorophyll content, larger number of flowers, and more fecund as compared to uninoculated plants. ${ }^{16}$ Inoculation of wheat and sorghum seedlings with PGPB demonstrated higher levels of cellular metabolites that increased plant tolerance to high temperatures. In general, PGPB inoculation not only alters the microbiome of plants, but also their metabolome. ${ }^{17}$ The direct effects of PGPB inoculation include enhancing water and nutrient uptake, and promoting homeostasis of phytohormones, whereas its indirect effect includes enhancing plant immunity against pathogens. ${ }^{4}$ As the agricultural industry is most vulnerable to global climate change, the use of PGPB in promoting drought tolerance in susceptible plants is a promising intervention. The current study advocates the need to isolate the most compatible and drought tolerant Bacillus species from hot arid region of India that promote drought tolerance and growth in wheat crop under drought stress conditions in climatic situation of Eastern Uttar Pradesh. 


\section{MATERIALS AND METHODOLOGY} Sample collection and isolation of Bacillus from rhizosphere soil

Rhizosphere soils were collected from wheat crop during the months of February-March 2017 from the four different sites of agricultural field in Roopsi and Sam villages of Jaisalmer district, Rajasthan India $\left(26.9107^{\circ} \mathrm{N} \& 70.9144^{\circ} \mathrm{E}\right.$ and $26.9798^{\circ} \mathrm{N}, 70.7525^{\circ} \mathrm{E}$ ), respectively. Crop plants of wheat were selected and uprooted, with the soil adhered to the roots, from each site and packed in zip locked polybags and transported to the laboratory. The rhizosphere soil was collected by removing the adhered soil from each plant. The putative Bacillus isolates were recovered from rhizosphere soil on nutrient agar (NA) medium supplemented with 5\% PEG-6000 using serial dilution method. Briefly, $0.1 \mathrm{ml}$ aliquot of each dilution was placed on Petri plates containing nutrient agar followed by incubation at $37^{\circ} \mathrm{C}$ for $48 \mathrm{~h}$. The visually distinct colonies were picked up and grew in nutrient broth in order to get pure colony of bacteria. Glycerol stocks (20\%) of each bacterium was prepared and stored at $-80{ }^{\circ} \mathrm{C}$ in a deep freezer. All the subsequent experiments were carried out using fresh cultures.

In vitro evaluation of drought tolerance potential of Bacillus isolates

\section{On solid medium using PEG}

Bacterial isolates were grown on NA medium supplemented with varied concentration of PEG-6000 (5-30\%) in order to select the most tolerant stain to drought conditions, simulated by osmotic pressure created by addition of PEG6000 followed by incubation of plates at $28 \pm 2$ ${ }^{\circ} \mathrm{C}$ for $48 \mathrm{~h}$. The growth of bacteria on PEG-6000 supplemented media was recorded. Isolates that survived at highest concentration of PEG6000 concentration were selected for further studies. ${ }^{18,19}$

\section{In broth medium using PEG}

Bacterial isolates were grown on nutrient broth (NB) supplemented with 10\%, 20\%, 30\%PEG 6000 equivalents to $-1.37 \mathrm{MPa}$ (Megapascal), -4.64 $\mathrm{MPa},-9.80 \mathrm{MPa}$ osmotic potential, respectively. The nutrient medium supplemented with PEG6000 was inoculated with $1 \mathrm{ml}$ of $10^{8} \mathrm{cfu} \mathrm{ml}^{-1}$ freshly grown culture followed by incubation at $28 \pm 2{ }^{\circ} \mathrm{C}$ up to $72 \mathrm{~h}$. Optical density (O.D.) of the culture was taken at $600 \mathrm{~nm}$. Lowry et a ${ }^{20}$ method was used to determine the protein concentration Uninoculated medium was used as negative control. Identification of putative Bacillus isolates

Two putative bacilli were identified at species level by morphological, biochemical, ${ }^{21}$ and $16 \mathrm{~S}$ rRNA gene sequencing methods. The sequencing of $16 \mathrm{~S}$ rRNA gene of two bacilli was performed using universal primers 27F1 (5- AGAGTTTGATCMTGGCTCAG-3) and 1494R (5-CTACGGCTACCTTGTTACGAC-3) at National Center for Microbial Resources (NCMR), Pune, India. The 16S rRNA gene sequences of isolates DT-89 and DT-113 were matched with type strains employing EzTaxon server ${ }^{22}$ and aligned by CLUSTAL $W$ in MEGA version $7^{23}$ software. The topology of evolutionary tree was evaluated by a bootstrap analysis ${ }^{24}$ of the $\mathrm{N}$-J method based on 1000 replicates by MEGA 7 software. The processed nucleotide sequences data were submitted in the NCBI GenBank to acquire accession number. Finally, the cultures of the Bacillus altitudinis DT-89 (NAIMCC-B-02229) and Bacillus paramycoides DT-113 (NAIMCC-B-02943) were deposited in NAIMCC (National Agriculturally Important Microbial Culture Collection), ICARNBAIM, Mau, Uttar Pradesh, India.

In vitro assessment of plant growth promoting traits of Bacillus spp. under stress conditions

Plant growth promoting attributes of selected strains were studied at three levels of drought stress (10\%, 20\%, and 30\% PEG-6000) and amended in all the media of the following tests. The bacterial strains were functionally characterized based on production of IAA, GA3, exopolysacharide, siderophore, hydrogen cyanide, ammonium production and ACC deaminase; solubilization of zinc, phosphorus, and antagonisms against phytopathogens by using standard procedures. Bacterial strains were tested for IAA production by procedure given by Ahmad et al. ${ }^{25}$ Bacterial stains were inoculated separately in $10 \mathrm{ml}$ Luria Bertani (LB) broth in $30 \mathrm{ml}$ tubes. Ten (10) ml LB broth containing supplemented with $200 \mathrm{mg} \mathrm{ml}^{-1}$ L-tryptophan and each tube was inoculated with $48 \mathrm{~h}$ grown $100 \mu \mathrm{l}\left(10^{8} \mathrm{ml}^{-1}\right)$ of culture followed by incubation at $28 \pm 2{ }^{\circ} \mathrm{C}$ for 4 days with shaking at 125 revolutions per minute ( $\mathrm{rpm}$ ) under normal and osmotic stress conditions. After incubation, a 5 $\mathrm{ml}$ culture of each bacterial strain was centrifuged at 9,000 rpm for $15 \mathrm{~min}$. Four (4) ml of Salkowski's 
reagent $\left(2 \% 0.5 \mathrm{M} \mathrm{FeCl}_{3}\right.$ in $35 \%$ perchloric acid) along with100 $\mu \mathrm{l}$ of orthophosphoric acid were added to $2 \mathrm{ml}$ of supernatant followed by incubation at $28 \pm 2^{\circ} \mathrm{C}$ in darkness for $1 \mathrm{~h}$. The development of pinkish to red colour indicated indole -3-acetic acid (IAA) production. Gibberellic acid (GA3) production by two strains was carried out under normal and osmotic stress conditions as per method of Burrows et al. ${ }^{26}$ Briefly, strains DT-89 and DT-113 were grown in LB broth and GA3 was estimated by extracting it with ethyl acetate and measuring absorbance at $680 \mathrm{~nm}$ spectrophotometrically. Exopolysaccharide production by two strains was estimated by gravimetric method. ${ }^{27}$ For siderophore production assay, bacterial culture was spot inoculated on Chrome Azurol S (CAS) agar and incubated at $28 \pm 2{ }^{\circ} \mathrm{C}$ for 3 days. The appearance of yelloworange halo around bacterial spot indicates of siderophore production. ${ }^{28}$ Quantitative estimation of siderophore was done according to the method of Payne et al. ${ }^{29}$ Zinc solubilization was assayed by streaking bacteria on Tris minimal agar medium supplemented separately with $0.1 \% \mathrm{Zn}$ as zinc oxide, zinc phosphate and zinc carbonate sources. Clear zone around bacterial colony was indicative of solubilization. For quantification of soluble $\mathrm{Zn}$, quantification of soluble $\mathrm{Zn}$ from three different insoluble sources solubilized by bacteria in Triminimal broth was assayed by using AAS using method described by Fasim et al. ${ }^{30}$ The bacterial strains were evaluated for phosphate solubilization on Pikovskaya agar using tricalcium phosphate as an insoluble source of phosphorus according to the standard method of Pikovskaya. ${ }^{31,32}$ The qualitative method of Kremer and Souissi ${ }^{33}$ was used to determine $\mathrm{HCN}$ production. Ammonia production was assayed by addition of $1 \mathrm{ml}$ Nesseler's reagent to $72 \mathrm{~h}$ grown cultures in peptone broth. The positive samples showed yellowish brown colour is an indicative for ammonium production. The ACC deaminase activity was studied as per the method described by Govindaswamy et al. ${ }^{34}$ The DT-89 and DT-113 strains were cultured in $5 \mathrm{ml}$ tryptone soya broth separately and incubated at $28 \pm 2{ }^{\circ} \mathrm{C}$ for $24 \mathrm{~h}$ at $120 \mathrm{rpm}$. The cell pellet was harvested by centrifugation at $6000 \mathrm{rpm}$ for 6 min followed by washing two times with sterile distilled water to remove traces of the medium. The washed pellet was suspended in $1 \mathrm{ml}$ sterile distilled water. The bacterium was spotted on Dworkin Foster (DF) minimal medium plates amended with $3 \mathrm{mM}$ of ACC, DF medium alone, a negative control, and DF medium containing ammonium sulphate, as a positive control. All the plates were observed after incubation at $28 \pm 2{ }^{\circ} \mathrm{C}$ for $96 \mathrm{hrs}$. The bacterium with prominent growth on ACC-DF was indicative of ACC deaminase production. Antagonistic potential of two strains was performed on PDA against Rhizoctonia solani, Macrophomina phaseolina, Fusarium oxysporum f.sp. cumini, F. oxysporum f. sp. carthami and Sclerotium rolfsii employing dual confrontation plate technique.

Plant growth promotion and drought tolerance potential of Bacillus spp. in pot culture

Two potential drought-adaptive bacteria strains namely DT-89 and DT-113 were taken for evaluation for their growth promoting and drought tolerance inducing ability on wheat crop (Var. HD-2967) in non-sterile soil under net house conditions. Inoculum of strains DT-89 and DT-113 was added in half strength NB and incubated at $28^{\circ} \mathrm{C}$ for $36 \mathrm{~h}$ and pellet of bacteria was obtained after centrifugation at $6000 \mathrm{rpm}$ for 12 min. Bacterial suspension was prepared in $0.85 \%$ aqueous saline solution of $0.5 \mathrm{OD}$ equivalent to

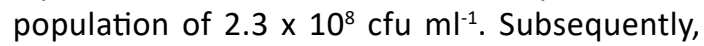
seeds of wheat were surface sterilized using $1.0 \%$ sodium hypochlorite by exposing it for $30 \mathrm{sec}$ and kept for some time to evaporate trace of sodium hypochlorite. Approximately, $50 \mathrm{~g}$ surface sterilized seeds were soaked in $50 \mathrm{ml}$ of 0.5 OD Bacillus species strains suspensions for one hour and then treated seeds were inoculated in the pots and kept in nethouse conditions in the winter of 2019 in Farm of ICAR-National Bureau of Agriculturally Important Microorganisms, Mau. Each pot was containing $10 \mathrm{Kg}$ of sieved ( $2 \mathrm{~mm}$ sieve) alluvial soil and was not fertilized with chemical fertilizers. In total, there were three treatments, (i) Absolute control without any bacterization, (ii) bacterization with DT-89 strain and (iii) bacterization with DT-113 strain with two conditions watered and stressed ( $50 \%$ - that is half dose of water). All the treatments were replicated three times and total 18 pots were used for two stages of sampling. Initially, each pot was sown with 6 seeds for germination and finally 3 seedlings were maintained for each pot throughout experimentation. After germination, plants were maintained under water 
and water stress conditions (50\%) throughout experimentation.Plants were harvested after 45 and 75 days, and the soil particles adhered on the roots was removed by washing with tap water. Phenotypic (root and shoot length fresh and dry weight) parameters of the harvested plants were recorded. The leaf samples were preserved at $4{ }^{\circ} \mathrm{C}$ for various biochemical estimations like ROS scavenging enzyme activities, proline and chlorophyll content. Chlorophyll content was determined in $80 \%$ acetone extract. The absorbance was read spectrophotometrically at 663 and $645 \mathrm{~nm}$. Total chlorophyll concentrations were calculated as per method of Arnon. ${ }^{35}$ Other parameters were also analysed as mentioned below.

Estimation of ROS scavenging stress marker enzymes and proline content

Assays of superoxide dismutase (SOD) ${ }^{37}$ and peroxidase (POD) ${ }^{38,39}$ activity were performed utilizing supernatant obtained by centrifuging $500 \mathrm{mg}$ of leaves in $1.5 \mathrm{ml}$ of $0.1 \mathrm{M}$ phosphate buffer ( $\mathrm{pH} 7$ ) at $18,000 \mathrm{~g}, 5^{\circ} \mathrm{C}, 15$ minutes.

SOD activity was assayed by measuring the inhibition of nitroblue tetrazolium (NBT) by SOD enzyme. Three $(3 \mathrm{ml})$ reaction mixture contained $100 \mu \mathrm{L}$ of crude extract, $50 \mathrm{mM}$ sodium phosphate buffer ( $\mathrm{pH}$ 7.6), $0.1 \mathrm{mM}$ EDTA, $50 \mathrm{mM}$ sodium carbonate, $12 \mathrm{mM}$ L-methionine, $50 \mu \mathrm{M}$ NBT and $10 \mu \mathrm{M}$ riboflavin. The reaction mixture without crude extract and irradiation served as blank, whereas SOD reaction was carried out by exposing the reaction mixture to white light for 15 $\mathrm{min}$ at room temperature. After $15 \mathrm{~min}$ incubation, absorbance was recorded at $560 \mathrm{~nm}$ using a spectrophotometer. One unit (U) of SOD activity was defined as the amount of enzyme causing $50 \%$ inhibition of photochemical reduction of NBT.

POD activity was determined by measuring the absorbance changes at $436 \mathrm{~nm}$ at $25^{\circ} \mathrm{C}$. The rate of formation of GDHP (guaiacol dehydrogenation product) in the guaiacol assay is a measure of the POD activity. The extinction coefficient for GDHP at $436 \mathrm{~nm}$ is $6.39 \mathrm{~cm}^{2}$ per $/ \mu$ mole guaiacol oxidized. ${ }^{38}$ Reaction mixture contained $3 \mathrm{ml}$ of the phosphate buffer solution (0.1M), $0.05 \mathrm{ml}$ guaiacol solution, $0.1 \mathrm{ml}$ enzyme extract and $0.03 \mathrm{ml}$ hydrogen peroxide solution in a cuvette. The mixture was well shaken and placed in the spectrophotometer. The time required for the mixture optical density to be increased by $0.1(\Delta t)$ at $436 \mathrm{~nm}$ was recorded. In this contribution, the resulting end product is called GDHP (guaiacol dehydrogenation product). Free proline was determined as per Bates et al. ${ }^{40}$ Briefly, $200 \mathrm{mg}$ of leaf sample was homogenized with $3 \%(w / v)$ aqueous sulfosalicylic acid and the supernatant obtained was treated with glacial acetic and ninhydrin at $100^{\circ} \mathrm{C}$ followed by cooling. Now, the chromophore was extracted with toluene by addition in the reaction mixture and finally reading was taken at $520 \mathrm{~nm}$. Proline content was expressed as $\mathrm{mg} \mathrm{g}^{-1}$ fresh weight basis.

\section{Statistical analysis}

All the experiments were performed in triplicates. Statistical analysis was done using Prism GraphPad (Version 9, CA USA) for obtaining $P$ values. Analysis of variance (ANOVA) was performed and the means were compared with Tukey's test at $\mathrm{P}<0.05, \mathrm{P}<0.001, \mathrm{P}<0.0001$. Microsoft Office Excel 2007 was used for graphics and determination of standard deviation.

\section{RESULTS}

\section{Screening of drought tolerant isolates}

A total of 113 isolates were recovered from wheat rhizosphere soils of 4 different sites of Jaisalmer district, Rajasthan state to screen out potential drought tolerant isolates. Out of 113 isolates screened for drought tolerance ability, $65(57 \%), 29(25 \%)$ and $9(8 \%)$ bacteria grew at $10 \%, 20 \%$ and $30 \%$ PEG-6000, respectively. Out of 9 isolates, only two potential bacterial isolates DT-89 and DT-113 were selected for further study. These two isolates had also shown tolerance to temperature up to $65^{\circ} \mathrm{C}$. Although, growth of two bacteria at $30 \%$ PEG- 6000 were low but they grew luxuriantly at $10 \%$ and $20 \%$ PEG concentration as compared to other bacteria tested in this study (Table 1). Isolate DT-113 was found more tolerant in comparison with isolate DT-89 as indicated by more growth by DT-113 under the stress of PEG6000.

Plant growth promoting traits under stress conditions in Bacillus spp.

The two isolates DT-89 and DT-113 had shown differential behavior with respect to display of functional properties. In general, both the isolates were found positive for production of EPS, IAA, GA 3, siderophore, ammonium and 


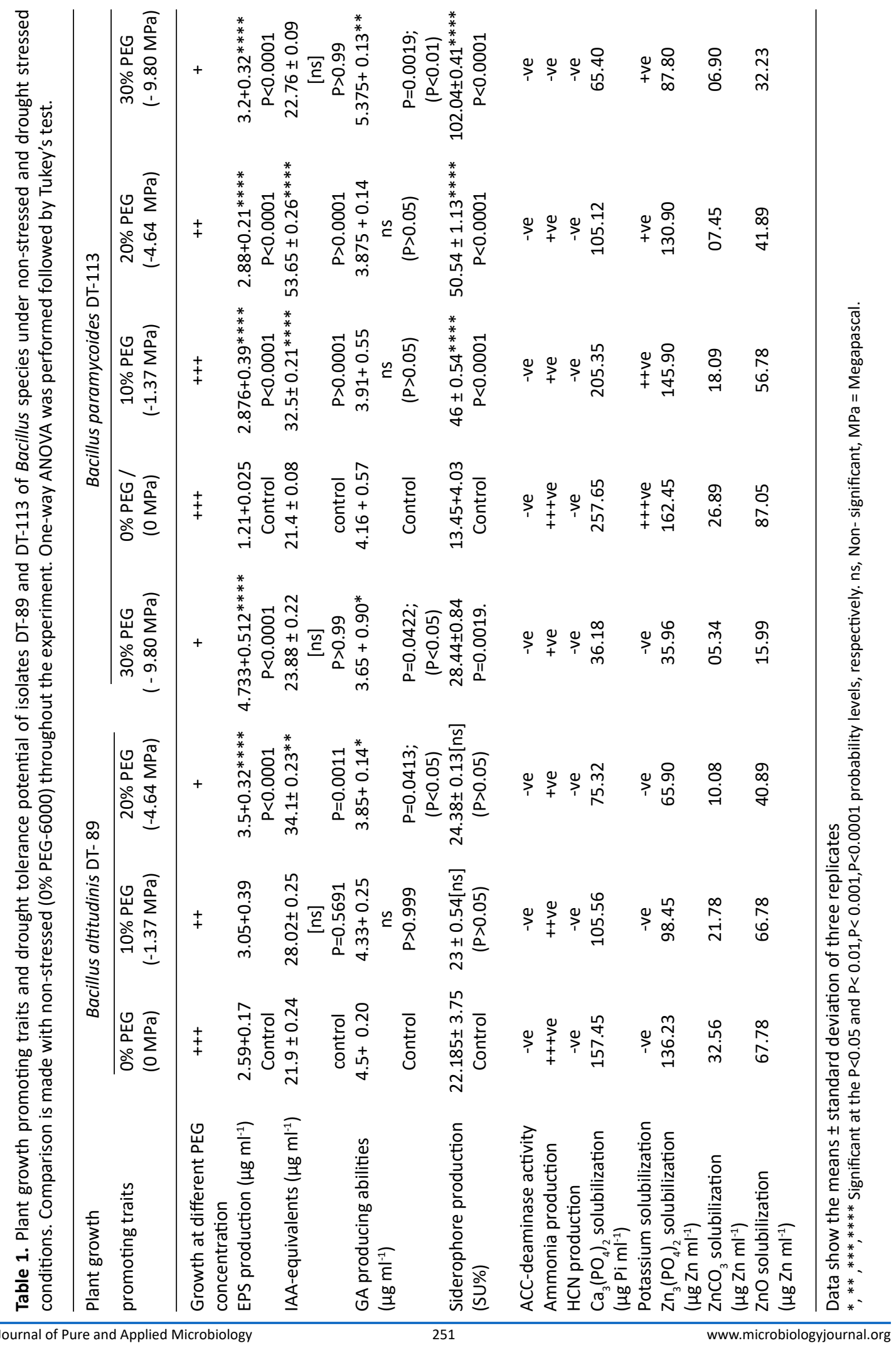


solubilization of $\mathrm{P}$ and $\mathrm{Zn}$ but no ACC deaminase and $\mathrm{HCN}$ production were obtained (Table 1). Isolate DT-89 showed $28 \%(P>0.05)$, $55.7 \%(P<0.001)$, and $9 \%(P>0.05)$ increase in IAA production at $10 \%, 20 \%$ and $30 \%$ PEG 6000 , respectively, in comparison to $0 \%$ PEG supplemented group. Similarly, isolate DT-89 showed increase in EPS by $17.765 \%, 35.13 \%$ and $19.30 \%(P<0.0001)$ in comparison to normal conditions. In case of isolate DT-113, a significant high increase of $137 \%, 137 \%$ and $164 \%(P<0.0001)$ was found in EPS content at $10 \%, 20 \%$ and $30 \%$ PEG 6000 concentration respectively. In comparison to no PEG condition, GA3 activity decreased insignificantly by $3.7 \%, 14.4 \%,(P<0.05)$ and $18.8 \%(\mathrm{P}<0.05)$, at $10 \%, 20 \%$ and $30 \% \mathrm{PEG} 6000$ supplementation respectively in DT-89. Further, insignificant $3.67 \%, 9.89 \%$, and significant $28.19 \%(P<0.05)$ increase was observed at $10 \%$, $20 \%$ and $30 \%$ PEG 6000 conditions, respectively, for siderophore production by isolate DT-89 in comparison to normal control. On the contrary, DT-113 showed significant increase ( $240 \%-658 \%$ ) in siderophore $(\mathrm{P}<0.0001)$ at all levels of stress conditions.

In case of isolate DT-113, significant increase of $51.86 \%(P<0.001)$ and $150.7 \%$ $(\mathrm{P}<0.0001)$ in IAA production were observed at $10 \%$ and $20 \% \mathrm{PEG}$, respectively, in comparison to normal conditions. On the contrary, the GA3 production showed a marked non-significant decrease of $6 \%, 6.8 \%$ and a significant increase of $29.2 \%(P<0.01)$ at $10 \%, 20 \%$ and $30 \%$ PEG 6000 by strain DT-113 in comparison to the normal condition.

EPS and siderophore production by both the isolates under stress of $30 \%$ PEG was highest whereas other traits like IAA, GA3, phosphateand zinc- solubilization reduced gradually up to $30 \%$ PEG. IAA production was also increased up to $20 \%$ stress level. Increase production of EPS, siderophore and IAA on increasing stress by increased percent of PEG 6000 might contribute to induction of stress tolerance in Bacillus. Both the isolates were able to solubilize calcium phosphate, zinc phosphate, zinc oxide and zinc carbonate but maximum solubilization was achieved in calcium phosphate $\left(257.65 \mathrm{\mu} \mathrm{Pi} \mathrm{ml}^{-1}\right)$ and zinc phosphate (162.45 $\mathrm{g} \mathrm{Zn} \mathrm{ml}^{-1}$ ) and least was noted with zinc carbonate $\left(5.34 \mu \mathrm{Zn} \mathrm{ml}^{-1}\right)$ (Table 1). Further,

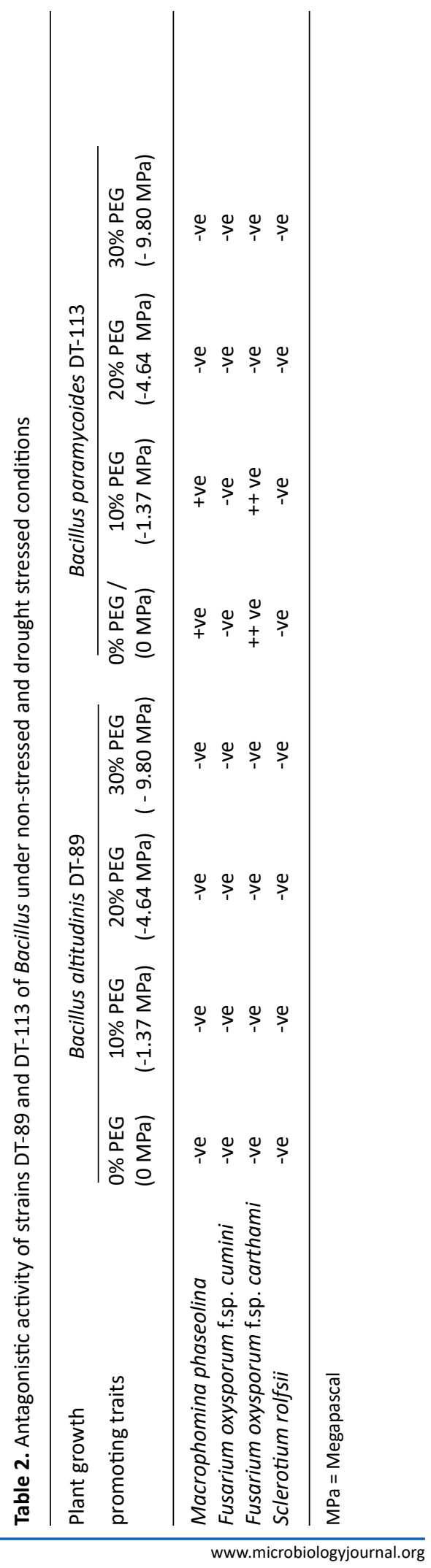


Table 3. Morphological, physiological, biochemical and molecular characterization of strains DT-89 and DT-113 of Bacillus species

\begin{tabular}{|c|c|c|}
\hline Characteristics & Bacillus altitudinis DT-89 & Bacillus paramycoides DT-113 \\
\hline Isolation source & Rhizosphere of wheat crop & Rhizosphere of wheat crop \\
\hline \multicolumn{3}{|l|}{ Morphological characteristics } \\
\hline \multicolumn{3}{|l|}{ Colony configuration } \\
\hline Colony margin & Undulate & Entire \\
\hline Colony elevation & Raised & Raised \\
\hline Colony surface & Rough & Smooth \\
\hline Colony pigmentation & Creamy white & Creamy white \\
\hline Gram reaction & + ve & + ve \\
\hline Endospore & + ve & + ve \\
\hline \multicolumn{3}{|l|}{ Physiological characteristics } \\
\hline Growth at/in & Aerobic & Aerobic \\
\hline Temperature, $15-37^{\circ} \mathrm{C}$ & +++ ve & +++ ve \\
\hline $\mathrm{pH}, 6.0$ & + ve & + ve \\
\hline $\mathrm{pH}, 7.0-10.0$ & +++ ve & +++ ve \\
\hline $\mathrm{NaCl}(\%)$ & $5 \%=+++$ ve & $5 \%=+++$ ve \\
\hline \multirow[t]{2}{*}{$4.0-15.0$} & $10 \%=-v e$ & $10 \%=+++$ ve \\
\hline & & $15 \%=-$ ve \\
\hline \multicolumn{3}{|l|}{ Biochemical characteristics } \\
\hline Indole production & - ve & - ve \\
\hline Methyl red test & ++ ve & ++ ve \\
\hline Voges-Proskauer test & - ve & - ve \\
\hline Citrate utilization & - ve & - ve \\
\hline \multicolumn{3}{|l|}{$\mathrm{H}_{2} \mathrm{~S}$ production } \\
\hline Oxidase & - ve & - ve \\
\hline Catalase & ++ ve & ++ ve \\
\hline Starch hydrolysis & + ve & + ve \\
\hline Nitrate reduction & - ve & + ve \\
\hline Casein/ protease hydrolysis & ++ ve & ++ ve \\
\hline \multicolumn{3}{|l|}{ Acid production from } \\
\hline Dextrose & +++ ve & +++ ve \\
\hline Lactose & - ve & ++ ve \\
\hline \multicolumn{3}{|l|}{ 16S rRNA gene sequence } \\
\hline NCBI Gene bank accession no. & MK547281 & MW959783 \\
\hline Accession of cultures deposited in MRC & NAIMCC-B-02229 & NAIMCC-B-02943 \\
\hline
\end{tabular}

+ve: positive; -ve: negative; MRC: Microbial Resource Centre

the extent of solubilization was reduced upon increasing level of stress. It is interesting to note that although ACC deaminase production is associated with induction of stress tolerance but none of the isolates showed significant production of ACC deaminase in this study. Both the isolates did not show any antagonism toward most of the phytopathogens except isolate DT-113 which showed weak antagonism to Fusarium oxysporum f.sp. carthami under no stress and stress of $10 \%$ PEG in this study (Table 2). Overall, isolate DT-113 displayed better stress tolerance and plant growth promoting attributes as compared to isolate DT-89. Identification of Bacillus isolates

The putative Bacillus isolates designated as isolates DT-89 and DT-113 were characterized by morphological, physiological, biochemical and $16 \mathrm{~S}$ rRNA gene sequencing methods (Table 3). The colony morphology of the isolate DT-89 was undulated, raised, rough with creamy white color pigmentation whereas DT-113 was entire, raised, smooth and creamy white. Under in 
vitro conditions, the isolates DT-89 and DT-113 can tolerate up to $5 \%$ and $10 \% \mathrm{NaCl}$,respectively and can withstand $\mathrm{pH} 7.0-10.0$ and temperature up to $65^{\circ} \mathrm{C}$. Both isolates DT- 89 and DT- 113 isolates were positive for methyl red, catalase, starch hydrolysis, casein hydrolysis, dextrose utilization, and negative for indole production, VogesProskauer test, citrate utilization, oxidase, nitrate reduction and lactose utilization. 16S rRNA gene sequence based phylogenetic analysis indicated that isolates DT-89 was found to be closely related to Bacillus altitudinis $41 \mathrm{KF} 2 \mathrm{~b}$ (99.01\%), and DT113 was similar to Bacillus paramycoides MCCC 1 A04098 (99.01\%) (Fig. 1).
Plant growth promotion and drought tolerance induction in wheat by Bacillus spp.

Two drought-tolerant Bacillus altitudinis DT-89 and Bacillus paramycoides DT-113 were assessed for their effect on plant growth promoting attributes, chlorophyll content and drought tolerance inducing ability on wheat crop under normal and water stress (drought stress) in net house conditions. In general, the growth associated traits such as shoot and root dry weight, and chlorophyll content were increased in inoculated plants at both normal and $50 \%$ water stress conditions over the uninoculated plants (Fig. 2). At 45 days, induction of drought stress

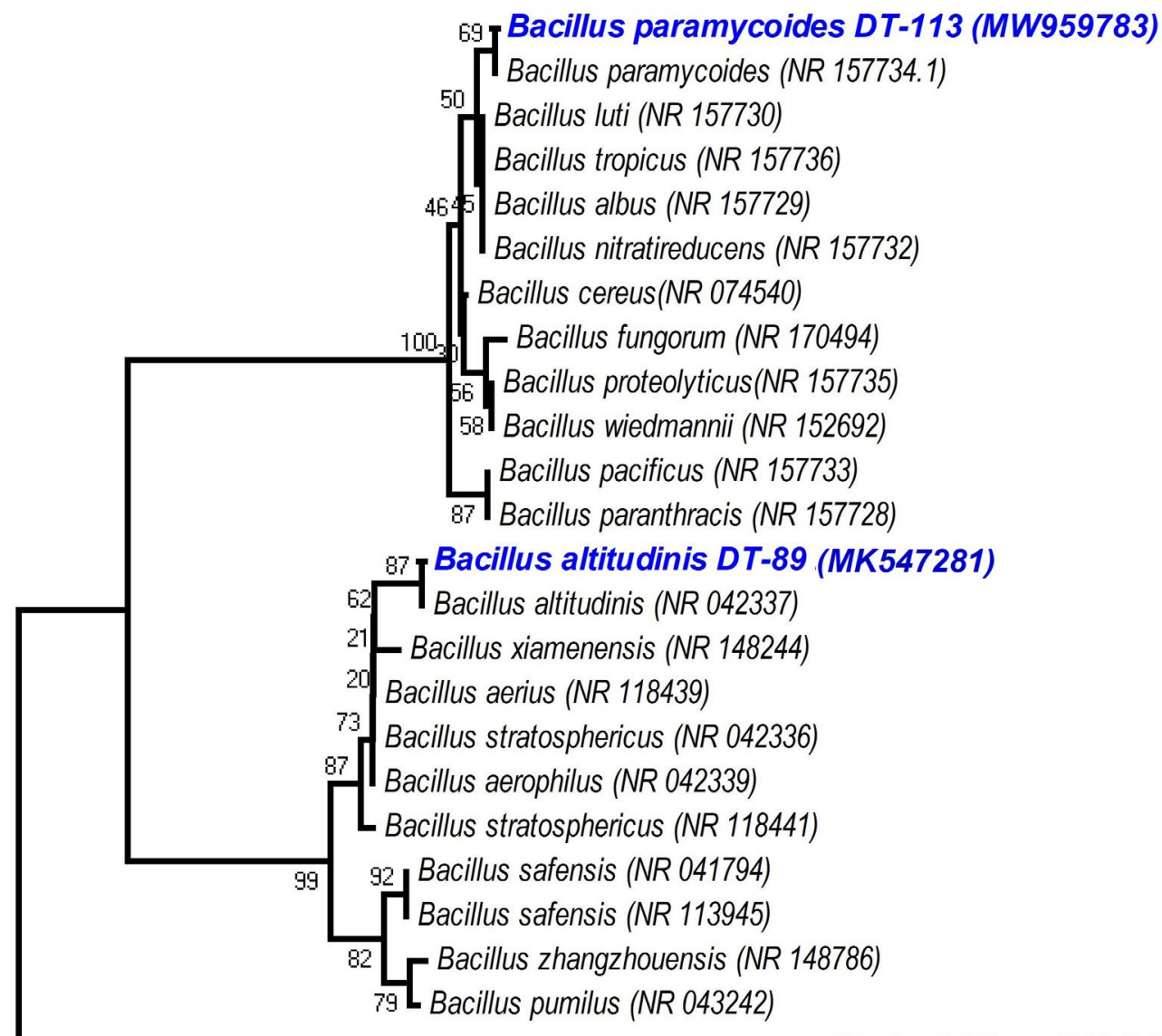

Escherichia coli (AJ567540)

0.02

Fig. 1. Phylogenetic tree generated with the neighbour-joining algorithm based on $16 \mathrm{~S}$ rRNA gene sequences showing the phylogenetic positions of DT-89, DT-113 strains and related taxa. Bootstrap values with more than $50 \%$ are shown on the nodes as percentages of 1000 replicates. The scale bar equals 0.005 change per nucleotide position. 
reduced shoot dry weight by $46.75 \%(\mathrm{P}<0.0001)$, $9.92 \%$ and $9.31 \%$ in uninoculated control, DT-89 and DT-113 strains, respectively, as compared to non-stressed condition (watered) Further, on comparison among treatments under drought stressed conditions, strains DT-89 and DT-113 enhanced $54.87 \%(P<0.0001)$ and $78.04 \%(P<$ 0.0001 ) shoot dry weight, respectively at 45 days of sowing. Similarly, after 75 days of sowing, induction of drought stress reduced shoot dry weight by 45.47\% ( $P<0.0001), 36.40 \%$ and $41.70 \%(P<0.0001)$ in uninoculated control, DT-89 and DT-113 strains, respectively as compared to watered condition. In case of root dry weight, induction of drought stress reduced root dry weight by significantly by $41.17 \%$ $(P<0.0001), 40.00 \%(P<0.0001)$ and $25.00 \%$ in uninoculated control, DT-89 and DT-113 strains, respectively, as compared to respective nonstressed condition (watered) (Fig.3) and 75.55\% $(P<0.0001)$ and $144.44 \%(P<0.0001)$ respectively after 75 days of sowing. Similarly, at 75 days of sowing induction of drought stress reduced shoot dry weight by $45 \%, 35.77 \%$ and $44.55 \%(P<0.0001)$ in uninoculated control, DT-89, and DT-113 strains respectively. In general, strains DT-89 and DT-113 inoculation induced drought tolerance as indicated by enhanced shoot and root dry weight noted both at 45 and 75 days and maximum being by strain DT-113. In case of chlorophyll content, at 45 days, drought reduced total chlorophyll content by $48.77 \%(P<0.0001)$ in uninoculated control but inoculation by DT-89 and DT-113 strains reduced $29.98 \%$ and $18.6 \%$, respectively in comparison to their respective normally watered plants groups. In comparison to uninoculated drought stress an increase of $175 \%(P<0.0001)$ and $150 \%(P<0.0001)$ by DT-89 and DT-113 respectively was observed for 45 days growth treatment. Similarly, at 75 days, drought reduced total chlorophyll content by $22.24 \%$ in comparison to uninoculated control (Fig. 4). Further under drought stress 39\% $(P<0.001)$ increase was recorded in DT-113 strain inoculated plants in comparison to drought control at 75 days treatment group.

Effect of PGPB inoculation on ROS scavenging enzymes and proline under drought stress

In general, drought stress increased superoxide dismutase (SOD), peroxidase (POD) and proline content in wheat plants under uninoculated control condition but inoculation of bacilli further enhanced the activity of enzymes and proline content (Fig. 5, Fig. 6, Fig. 7). Bacillus altitudinis DT-89 showed a significant variation of $137 \%(P<0.0001)$ in SOD activity at 45 days but

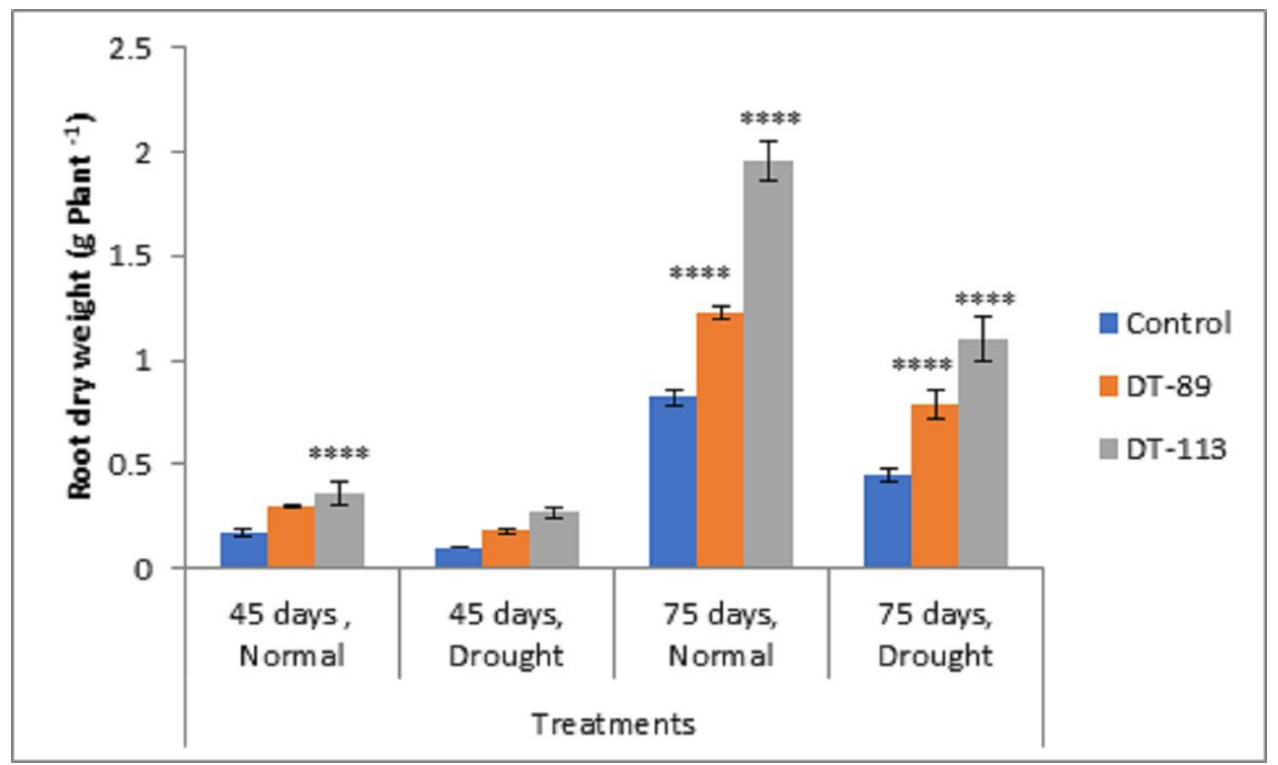

Fig. 2. Influence of Bacillus altitudinis DT-89 and Bacillus paramycoides DT-113 on root dry weight (g) in wheat crop (HD-2967) after 45 and 75 days of sowing under non-stressed and drought (water) stressed conditions. Data represent means $\pm S D, n=3$. Significance levels are represented as $*(P<0.05), * *(P<0.01), * * *(P<0.001), * * * *(P<0.0001)$. 
$214 \%$ increase $(P<0.0001)$ in SOD activity in 75 days treatment in comparison to untreated plants. Similarly, Bacillus paramycoides DT-113 showed $151 \%(P<0.0001)$, and 389\% increase $(P<0.0001)$ in SOD activity at 45 days and 75 days treatment groups respectively in comparison to uninoculated drought control. The SOD content was higher at 75 days as compared to 45 days with maximum SOD as noted upon inoculation of strain DT-113. However, POD activity was increased by $90 \%(P<0.0001)$ and $19.63 \%$ ( $P>0.05$ ) by DT-89 treatment at 45 days and 75 days period respectively under drought stress

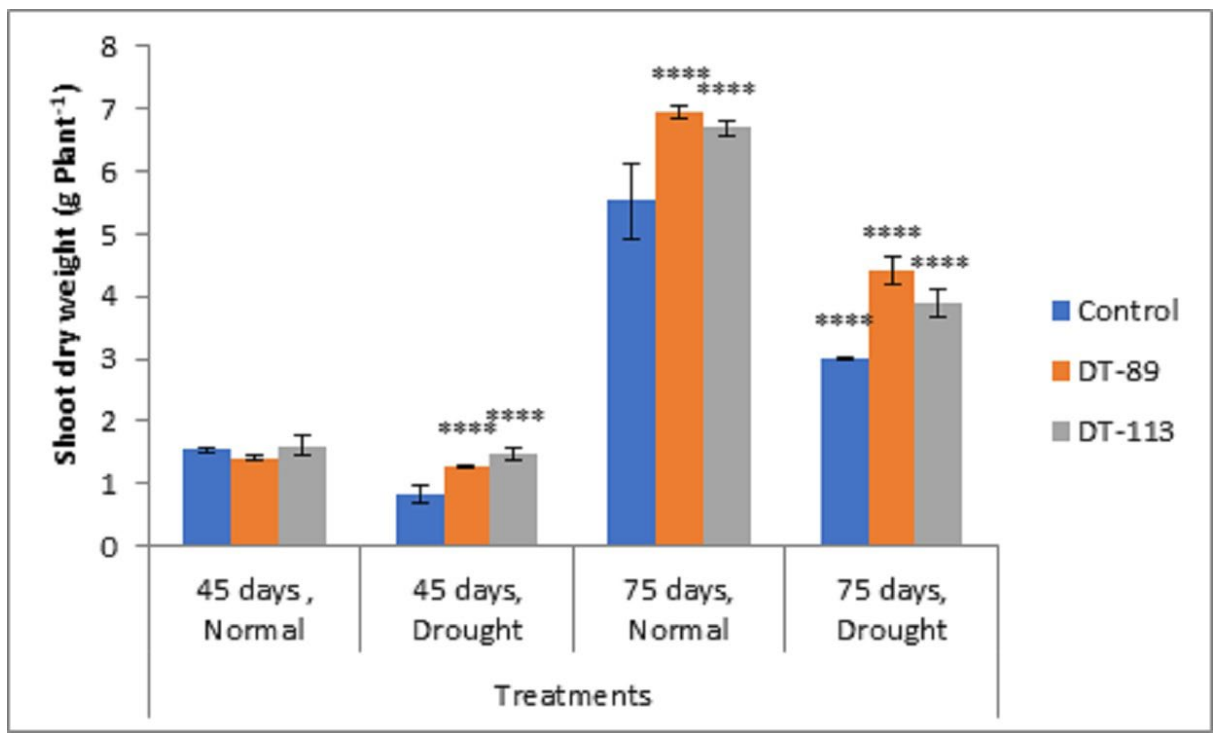

Fig. 3. Influence of Bacillus altitudinis DT-89 and Bacillus paramycoides DT-113 on shoot dry weight (g) in wheat crop (HD-2967) after 45 and 75 days of sowing under non-stressed and drought (water) stressed conditions. Data represent means $\pm S D, n=3$. Significance levels are represented as $*(P<0.05), * *(P<0.01), * * *(P<0.001), * * * *(P<0.0001)$.

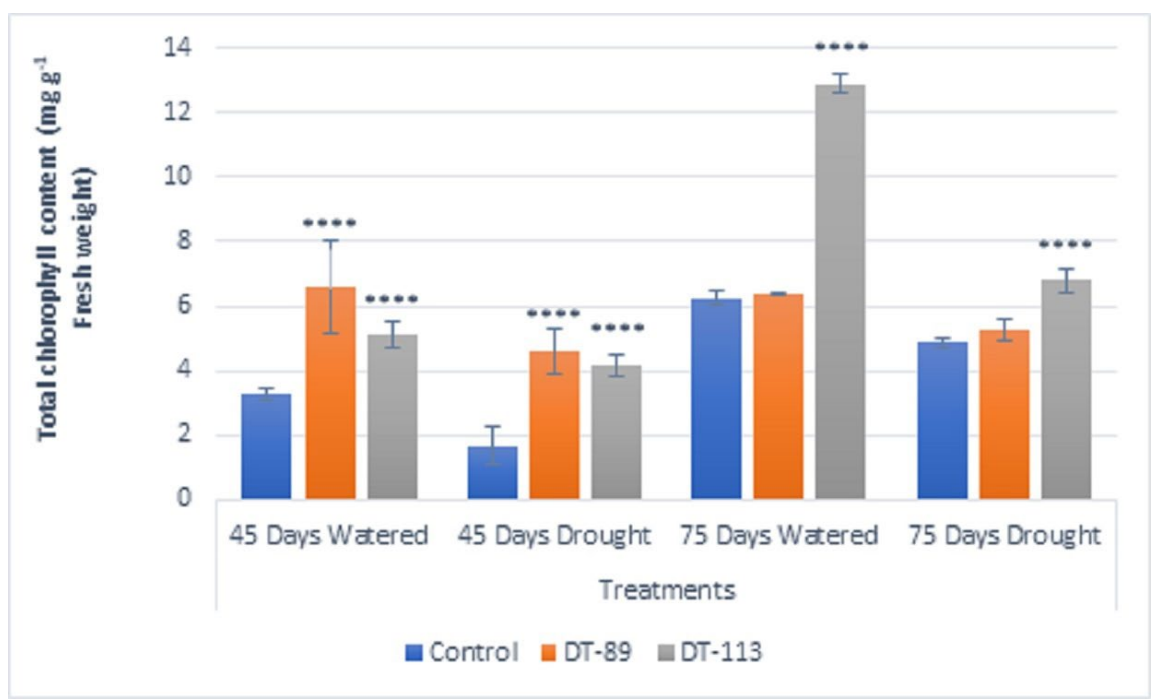

Fig. 4. Influence of Bacillus altitudinis DT-89 and Bacillus paramycoides DT-113 on total chlorophyll (mg g gresh $^{-1}$ weight) in wheat crop (HD-2967) after 45 and 75 days of sowing under non-stressed and drought (water) stressed conditions. Data represent means $\pm S D, n=3$. Significance levels are represented as $*(P<0.05), * *(P<0.01)$, $* * *(\mathrm{P}<0.001), * * * *(\mathrm{P}<0.0001)$. 
in comparison to uninoculated drought control. While DT-113 exhibited $36 \%$ and $21 \%$ increase of drought activity in comparison to drought control. Level of proline content was enhanced by inoculation of bacilli irrespective of unstressed and drought stressed conditions, but drought stressed plants retained more proline content. Strain DT-89 increased proline by $39.28 \%(P<0.0001)$ and $155 \%$ $(\mathrm{P}<0.0001)$ at 45 days and 75 days treatment, respectively, in comparison to uninoculated control drought plants. In case of strain DT-113 treated plants proline value increased by $70.24 \%$ $(P<0.0001)$ and $99.3 \%(P<0.0001)$ in 45 days and 75 days treatment plants, respectively, in comparison to uninoculated control drought stressed plants. Under drought stress condition, inoculation of strains DT-89 and DT-113 further stimulated production of proline suggesting positive role

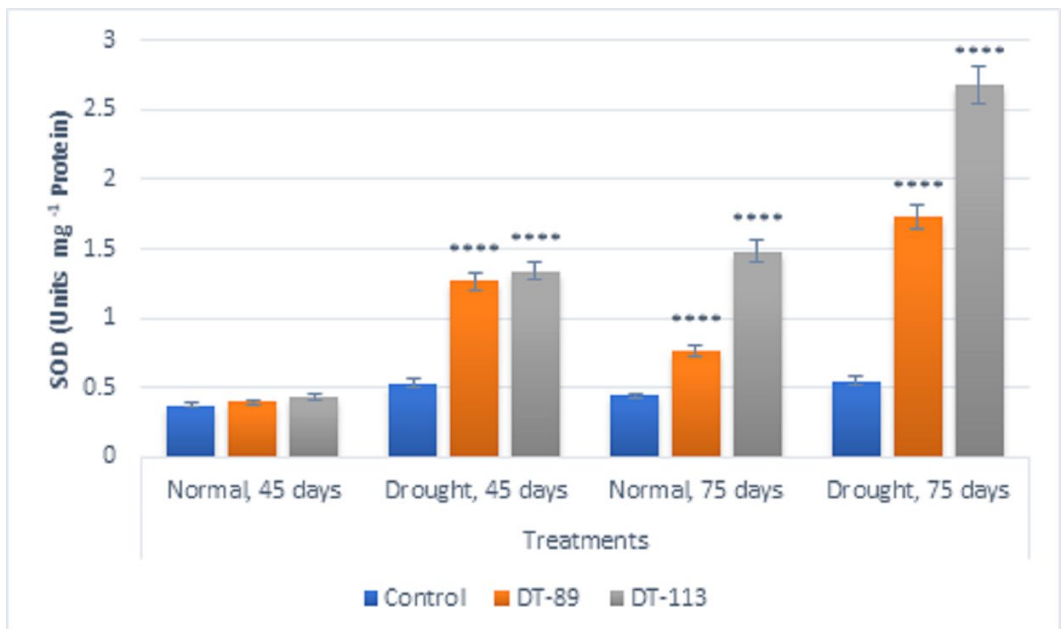

Fig. 5. Influence of Bacillus altitudinis DT-89 and Bacillus paramycoides DT-113 on drought induced enzymes superoxide dismutase (SOD) levels (Unit mg ${ }^{-1}$ protein) in wheat crop (HD-2967) after 45 and 75 days of sowing under non-stressed and drought (water) stressed conditions. Data represent means $\pm S D, n=3$. Significance levels are represented as * $(\mathrm{P}<0.05), * *(\mathrm{P}<0.01), * * *(\mathrm{P}<0.001), * * * *(\mathrm{P}<0.0001)$

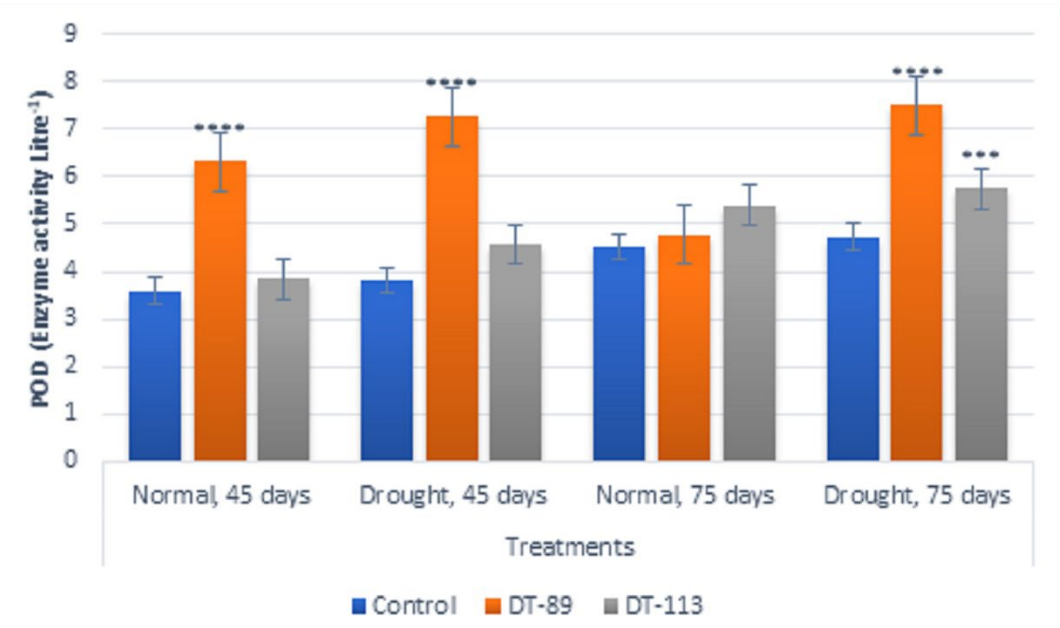

Fig. 6. Influence of Bacillus altitudinis DT-89 and Bacillus paramycoides DT-113 on drought induced enzymes Peroxidase (POD) levels (Enzyme unit $\mathrm{L}^{-1}$ ) in wheat crop (HD-2967) after 45 and 75 days of sowing under non-stressed and drought (water) stressed conditions. Data represent means $\pm S D, n=3$. Significance levels are represented as $*(\mathrm{P}<0.05), * *(\mathrm{P}<0.01), * * *(\mathrm{P}<0.001), * * * *(\mathrm{P}<0.0001)$ 
of bacilli in improvement in plant growth under drought stress. Based on above results, it has been inferred that Bacillus altitudinis DT-89 and Bacillus paramycoides DT-113 have the ability to promote plant growth and inducing drought tolerance in wheat plant by enhancing enzymes and proline production.

\section{DISCUSSION}

The bacilli represent an important member of microbial community present in soil. Studies have found that Bacillus species occur predominantly in the rhizosphere of wheat and barley. ${ }^{41,42}$ Bacillus species have bestowed with properties like endospore formation that help them to survive in the rhizosphere under abiotic stress and thus can manifest their role as plant growth promoting rhizobacteria by diverse modes of action. They can exhibit important mechanisms of biological control, biostimulation and biofertilisation. ${ }^{43}$ In the present study, 113 isolates of Bacillus were screened out for drought tolerance behavior and out of which Bacillus altitudinis DT-89 and Bacillus paramycoides DT-113 have been chosen based on their ability to survive under high water stress conditions and possess plant growth promoting ability. Two strains DT-89 and DT-113 were isolated from rhizosphere of wheat crop grown at different agricultural sites of Jaisalmer district of Rajasthan state, India in assumption that they will exert drought stress tolerance in wheat crop cultivated in northern Gangetic plain where drought stress prevails continually. The drought tolerance ability present in many bacteria like Pseudomonas, Burkholderia, Pantoea and other genera but Bacillus species are predominantly fall in the category of drought tolerance. Multiple reports supported the use of Bacillus as promising bacteria as they exhibit high degree of adaptability to diverse environmental stress conditions owing to endospore formation capability. Various strains of Bacillus species like Bacillus subtilis GB03, B. amyloliquefaciens FZB4244, Bacillus spp. produce important metabolites thus are being used in biofertilizer and biopesticide formulations. Vardharajulu et $\mathrm{a}^{45}$ reported strains of Bacillus namely $B$. licheniformis, B. amyloliquefaciens, B. thuringiensis, B.subtilis and Paenibacillus favisporus can alleviate negative response of drought by increasing root adhering soil/root tissue ratio, soil aggregate stability, plant biomass, relative water content, leaf water potential, preventing leaf water loss. Also, Bacillus spp. increased sugars, proline, free amino acids, reduced electrolyte leakage as well as decreased antioxidant enzymes like catalase, glutathione peroxidase, ascorbate peroxidase. For example, Moreno-Galvan et al. ${ }^{46}$ evaluated five Bacillus

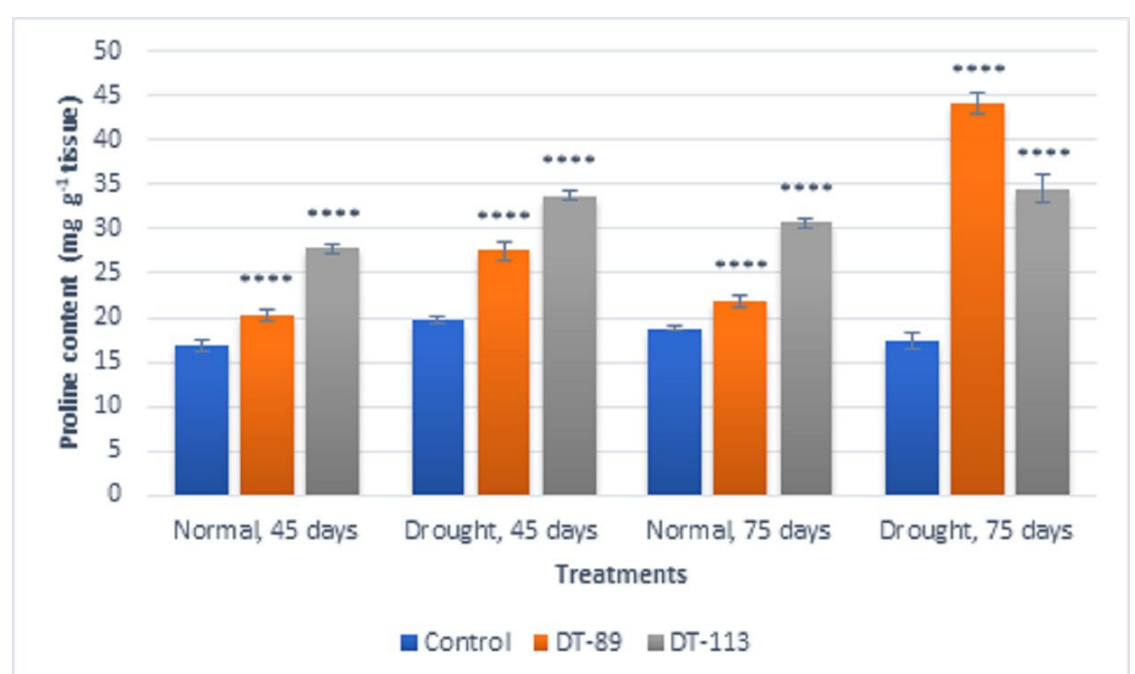

Fig. 7. Effect of Bacillus altitudinis DT-89 and Bacillus paramycoides DT-113 on proline content ( $\mathrm{mg} \mathrm{g}^{-1}$ tissue) in wheat crop (HD-2967) after 45 and 75 days of sowing under non-stressed and drought (water) stressed conditions. Data represent means $\pm S D, n=3$. Significance levels are represented as $*(P<0.05),{ }^{* *}(P<0.01), * * *(P<0.001)$, $* * * *(\mathrm{P}<0.0001)$. 
spp. strains which ameliorated drought stress by increasing plant height, dry biomass and $\mathrm{K}^{+}$ and $\mathrm{P}^{+}$uptake in maize plants. Bacillus species are reported to upgrade ability of plants to resist adverse environmental abiotic stresses including drought. Bacillus synergize with other root harboring microbes to promote plant growth, mineral nutrition, and conferring stress tolerance. ${ }^{47}$

In the present study, Bacillus altitudinis DT-89 and Bacillus paramycoides DT-113 had shown tolerance up to $30 \%$ of PEG 6000 indicating their high-level tolerance which is in agreement with Vardharajulu et al. ${ }^{45}$ who reported that $B$. amyloliquefaciens, $B$. subtilis and $B$. licheniformis could tolerate up to $25 \%$ of water stress. In this study, our strains DT-89 and DT-113 have displayed a few PGP traits such as production of siderophore, ammonia, exopolysaccharide (EPS), IAA, GA3 and solubilization of zinc, phosphate and potassium under non-stressed and drought stress conditions. These properties have been reported as markers for biofertilization, biostimulation, and biocontrol by Bacillus species isolated from wheat rhizospheres. ${ }^{42}$ The potential of PGPB for phosphate solubilization and siderophores production is considered an essential trait to promote its growth and suppress the growth of soil pathogens. Additionally, by inducing the production of phytohormones and other metabolites in plants, PGPB enhances the plant's capability to thrive under environmental stressors. ${ }^{48}$ Production of biomolecules by DT-89 and DT-113 strains under drought stress conditions is of special significance because in arid areas they extend these benefits for plant growth promotion under harsh conditions. In this study, most of the tested PGP traits were found to be expressed under osmotic stress conditions too. Traits like siderophore production, exopolysaccharide production, and gibberellic acid production were found to be highest at 30\% PEG-6000 in the growth medium. On the other hand, the production of IAA was found to be highest in the presence of $20 \%$ PEG-6000 and was non-significantly changed in the presence of $30 \%$ PEG-6000. These findings are in contrast to those reported by Bandeppa et al., ${ }^{15}$ who found the maximum expression of most PGP traits in the presence of 20\% PEG-6000 in the growth media. Additionally, Sandhya et al., ${ }^{49}$ reported a decrease in expression of PGP traits upon exposure to water deficit stress when compared to normal growth conditions. However, in the present study, we found a beneficial outcome of osmotic stress on the expression of PGP traits in these two strains.

In the presence of environmental stressors, it has been reported that plant phytohormone production is disturbed thereby affecting plant growth and seed germination. External application of these phytohormones to plants exposed to drought has the capability to enhance plant growth. ${ }^{50}$ Therefore, production of phytohormones is considered to be an important PGP trait. In this study, the strains were found to produce IAA and GA 3 upon exposure to osmotic stress, therefore having the potential to supplement the endogenous plant hormones and contribute to plant growth under stress conditions. It also has potential to enhance seedling vigor and seed germination upon inoculation of drought stressed plants with these strains. ${ }^{15}$ Production of exopolysaccharide by the bacteria has also been reported to improve stress resistance in plants by enhancing water retention and mitigating drought stress. ${ }^{51}$ In the present study, both strains showed the capability of exopolysaccharide production under osmotic stress which is an important PGP trait for promoting drought tolerance in plants.

Plant growth promotion and drought stress tolerance induction in wheat and other crops by inoculation of Bacillus species have been documented by many researchers in the past. For example, Devarajan et $a^{52}$ reported induction of stress tolerance in rice by Bacillus endophyticus $\mathrm{PB} 3$, B. altitudinis PB46, and B. megaterium PB50. Likewise, Sunar et al. ${ }^{53}$ isolated the $B$. altitudinis strain from the rhizosphere region of Sechium edule plant in Darjeeling and demonstrated its root and shoot growth promotion properties under drought conditions. A decline in chlorophyll content and photosynthetic rate under drought stress was reported by inoculation of PGPR Bacillus subtilis HAS31. ${ }^{54}$ Other reports suggested similar results of decreased chlorophyll content in drought stress ${ }^{55}$ Alteration in chloroplast structure and its photo-oxidation by oxidative stress in drought affects the photosynthetic productivity. 4,56 Proteomics studies on molecular and physiological mechanisms of effect of Bacillus velezensis 5113 on 
abiotic stress including drought suggests their role in preserving the plant photosynthetic machinery by maintaining higher contents of photosynthetic pigments..$^{57}$ Bacillus amyloliquefaciens 5113 and Azospirillum brasilense NO40 improved drought stress tolerance in wheat, by increasing root growth and lateral root formation. ${ }^{58}$ Similarly, Rashid et $\mathrm{al}^{43}$ who reported that Bacillus megaterium and $B$. licheniformis induced drought tolerance in wheat by enhancing relative water content (59\%), chlorophyll a, b and carotenoid $(260,174$ and $70 \%)$, protein content (136\%), proline content $(117 \%), \%)$, fresh weight (35-192\%), and dry weight (58-226\%) of wheat and decreasing in MDA content (57\%). Our results suggest that Bacillus altitudinis DT-89 and Bacillus paramycoides DT-113 have ability to increase shoot and root biomass, chlorophyll, SOD, POD, and proline content in the wheat crop under drought stress to a significant level.

\section{CONCLUSION}

In this study, two potential droughttolerant Bacillus altitudinis DT-89 and Bacillus paramycoides DT-113 were isolated from the rhizosphere of wheat crop from Jaisalmer district of Rajasthan state, India. The two DT-89 and DT-113 strains were found to exhibit tolerance to around $30 \%$ PEG-6000 stress under in vitro condition and at the same time they displayed multitudes of traits pertaining to plant growth promotion. In addition, their inoculation improved shoot, root, chlorophyll content, SOD, POD and proline content in wheat plant under drought stress conditions. Of two strains, Bacillus paramycoides DT-113 had stimulated wheat growth maximum by conferring drought stress tolerance. Hence, Bacillus paramycoides DT-113 may be advocated as a bioinoculant for enhancing plant growth and imparting drought stress tolerance to wheat crop under water deficit condition prevailing in many parts of India.

\section{ACKNOWLEDGMENTS}

The authors are grateful to the Director, ICAR-NBAIM, Mau and the authorities of Amity University Noida for infrastructures and facilities provided during this study. The authors are also thankful to Mr Alok Upadhaya for rendering technical assistance during experimentation and to process for allotting accession number to bacterial cultures deposited to NAIMCC.

\section{CONFLICT OF INTEREST}

The authors declare that there is no conflict of interest.

\section{AUTHORS' CONTRIBUTION}

SKS and NB conceived and designed the experiements. VKY conducted experiments, collected data and prepared first draft of the manuscript. NB and SKS revised the manuscript and structured the work in proper shape. All the authors revised manuscript and approved final version for submission.

\section{FUNDING}

None.

\section{DATA AVAILABILITY}

All datasets generated or analyzed during this study are included in the manuscript.

\section{ETHICS STATEMENT}

Not Applicable.

\section{REFERENCES}

1. Lesk C, Rowhani P, Ramankutty N. Influence of extreme weather disasters on global crop production. Nature. 2016;529(7584):84-87. doi: 10.1038/nature16467

2. Daryanto $S$, Wang L, Jacinthe PA. Global synthesis of drought effects on maize and wheat production. PLOS ONE. 2016;11(5):e0156362. doi: 10.1371/journal. pone.0156362

3. Zhang J, Zhang $S$, Cheng $M$, et al. Effect of drought on agronomic traits of rice and wheat: A Meta-Analysis. Int J Environ Res Public Health. 2018;15(5):839. doi: 10.3390/ijerph15050839

4. Abid M, Ali S, Qi LK, et al. Physiological and biochemical changes during drought and recovery periods at tillering and jointing stages in wheat (Triticum aestivum L.). Sci Rep. 2018;8(1):4615. doi: 10.1038/s41598-01821441-7

5. Vurukonda SSKP, Vardharajula S, Shrivastava M, Ali SkZ. Enhancement of drought stress tolerance in crops by plant growth promoting rhizobacteria. Microbiol Res. 2016;184:13-24. doi: 10.1016/j.micres.2015.12.003

6. Yadav VK, Raghav M, Sharma SK, Bhagat N. Rhizobacteriome: Promising candidate for conferring drought tolerance in crops. J Pure Appl Microbiol. 2020;14(1):73-92. doi: 10.22207/JPAM.14.1.10

7. Marasco R, Rolli E, Ettoumi B, et al. A drought resistancepromoting microbiome is selected by root system under desert farming. PloS One. 2012;7(10):e48479. 
doi: 10.1371/journal.pone.0048479

8. Camaille M, Fabre N, Clement C, Ait Barka E. Advances in wheat physiology in response to drought and the role of plant growth promoting rhizobacteria to trigger drought tolerance. Microorganisms. 2021;9(4):687. doi: 10.3390/ microorganisms 9040687

9. Casanovas EM, Barassi CA, Sueldo RJ. Azospirillum inoculation mitigates water stress effects in maize seedlings. Cereal Res Commun. 2002;30(3):343-350. doi: 10.1007/BF03543428

10. Saravanakumar D, Kavino M, Raguchander T, Subbian P, Samiyappan R. Plant growth promoting bacteria enhance water stress resistance in green gram plants. Acta Physiol Plant. 2011;33(1):203-209. doi: 10.1007/ s11738-010-0539-1

11. Munns R. Comparative physiology of salt and water stress. Plant Cell Environ. 2002;25(2):239-250. doi: 10.1046/j.0016-8025.2001.00808.x

12. Kohler J, Hernandez JA, Caravaca F, Roldan A. Plantgrowth-promoting rhizobacteria and arbuscular mycorrhizal fungi modify alleviation biochemical mechanisms in water-stressed plants. Funct Plant Biol. 2008;35(2):141-151. doi: 10.1071/FP07218

13. Bhagat N, Raghav M, Dubey S, Bedi N. Bacterial exopolysaccharides: Insight into their role in plant abiotic stress tolerance. J Microbiol Biotechnol. 2021;31(8):1045-1059. doi: 10.4014/jmb.2105.05009

14. Kavamura VN, Santos SN, da Silva JL, et al. Screening of Brazilian cacti rhizobacteria for plant growth promotion under drought. Microbiol Res. 2013;168(4):183-191. doi: 10.1016/j.micres.2012.12.002

15. Bandeppa S, Paul S, Thakur JK, et al. Antioxidant, physiological and biochemical responses of drought susceptible and drought tolerant mustard (Brassica juncea L.) genotypes to rhizobacterial inoculation under water deficit stress. Plant Physiol Biochem. 2019;143:19-28. doi: 10.1016/j.plaphy.2019.08.018

16. Lau JA, Lennon JT. Evolutionary ecology of plantmicrobe interactions: soil microbial structure alters selection on plant traits. New Phytol. 2011;192(1):215224. doi: 10.1111/j.1469-8137.2011.03790.x

17. Schmidt R, Koberl M, Mostafa A, et al. Effects of bacterial inoculants on the indigenous microbiome and secondary metabolites of chamomile plants. Front Microbiol. 2014;5:64. doi: 10.3389/fmicb.2014.00064

18. Michel BE, Kaufmann MR. The osmotic potential of polyethylene glycol 6000. Plant Physiol. 1973; 51(5):914-916. doi: 10.1104/pp.51.5.914

19. Sandhya V, Ali SZ, Grover M, Reddy G, Venkateswarlu B. Alleviation of drought stress effects in sunflower seedlings by the exopolysaccharides producing Pseudomonas putida strain GAP-P45. Biol Fertil Soils. 2009;46(1):17-26. doi: 10.1007/s00374-009-0401-z

20. Lowry OH, Rosebrough NJ, Farr AL, Randall RJ. Protein measurement with the Folin phenol reagent. J Biol Chem. 1951;193:265-275. doi: 10.1016/S00219258(19)52451-6

21. Cappuccino JG, Sherman N. Biochemical activities of microorganisms. Microbiology, A Laboratory Manual. The Benjamin/Cummings Publishing Co. California, USA. 1992:188-247.

22. Kim OS, Cho YJ, Lee K, et al. Introducing EzTaxon-e:
A prokaryotic 16S rRNA gene sequence database with phylotypes that represent uncultured species. Int J Syst Evol Microbiol. 2012;62:716-721. doi: 10.1099/ ijs.0.038075-0

23. Tamura K, Stecher G, Peterson D, Filipski A, Kumar S. MEGA6: molecular evolutionary genetics analysis version 6.0. Mol Biol Evol. 2013;30(12):2725-2729. doi: $10.1093 / \mathrm{molbev} / \mathrm{mst} 197$

24. Felsenstein J. Confidence limits on phylogenies: an approach using the bootstrap. Evolution. 1985;39(4):783-791. doi: 10.1111/j.1558-5646.1985. tb00420.x

25. Ahmad E, Sharma SK, Sharma PK. Deciphering operation of tryptophan-independent pathway in high indole-3-acetic acid (IAA) producing Micrococcus aloeverae DCB-20. FEMS Microbiol Lett. 2020;367(24). doi: 10.1093/femsle/fnaa190

26. Burrows A, Brain PW, Chester VE, et al. Gibberellic acid, a metabolic product of the fungus Gibberella fujikuroi: Some observation on its production and isolation. J Food Agric. 1955;6(6):340-348. doi: 10.1002/ jsfa.2740060609

27. Sabra W. Microaerophilic production of alginate by Azotobacter vinelandii. Technische Universitat Braunschweig, Braunschweig, Germany. PhD dissertation. 1999.

28. Schwyn B, Neiland JB. Universal chemical assay for the detection and determination of siderophores. Anal Biochem. 1987;160(1):47-56. doi: 10.1016/00032697(87)90612-9

29. Payne SM. Detection, isolation and characterization of siderophores. Methods Enzymol. 1994;235:329-344. doi: 10.1016/0076-6879(94)35151-1

30. Fasim F, Ahmed N, Parsons R, Gadd GM. Solubilization of zinc salts by a bacterium isolated from the air environment of a tannery. FEMS Microbiol Lett. 2002;213(1):1-6. doi: 10.1111/j.1574-6968.2002. tb11277.x

31. Pikovskaya RI. Mobilization of phosphorus in soil connection with vital activity of some microbial species. Microbiology. 1948;17:362-370.

32. Aleksandrov VG, Blagodyr RN, llev IP. Liberation of phosphoric acid from apatite by silicate bacteria. Mikrobiol Zhurnal (Kiev). 1967;29:111-114.

33. Kremer RJ, Souissi T. Cyanide production by rhizobacteria and potential for suppression of weed seedling growth. Curr Microbiol. 2001;43(3):182-186. doi: 10.1007/s002840010284

34. Govindasamy V, Senthilkumar M, Mageshwaran V, Annapurna K. Detection and characterization of ACC deaminase in plant growth promoting rhizobacteria. J Plant Biochem Biotechnol. 2009;18(1):71-76. doi: 10.1007/BF03263298

35. Arnon AN. Method of extraction of chlorophyll in the plants. Agron J. 1967;23:112-121.

36. Beauchamp C, Fridovich I. Superoxide dismutase: improved assays and an assay applicable to acrylamide gels. Anal Biochem. 1971;44(1):276-287. doi: 10.1016/0003-2697(71)90370-8

37. Dhindsa RS, Dhindsa PP, Thorpe TA. Leaf senescence: Correlated with increased levels of membrane permeability and lipid peroxidation, and decreased 
levels of superoxide dismutase and catalase. J Exp Bot. 1981;32(1):93-101. doi: 10.1093/jxb/32.1.93

38. Putter J. Peroxidases. In Methods of Enzymatic Analysis. Academic Press, 1974:685-690. doi: 10.1016/ B978-0-12-091302-2.50033-5

39. Hammerschmidt R, Nuckles E, Kuc J. Association of enhanced peroxidase activity with induced systemic resistance of cucumber to Colletotrichum lagenarium. Physiol Plant Pathol. 1982;20(1):73-82. doi: 10.1016/0048-4059(82)90025-X

40. Bates LS, Waldren RP, Teare ID. Rapid determination of free proline for water-stress studies. Plant Soil. 1973;39(1):205-207. doi: 10.1007/BF00018060

41. Maplestone PA, Campbell R. Colonization of roots of wheat seedlings by bacilli proposed as biocontrol agents against take-all. Soil Biol Biochem. 1989;21(4):543-550. doi: 10.1016/0038-0717(89)90128-4

42. Cherif-Silini H, Silini A, Yahiaoui B, Ouzari I, Boudabous A. Phylogenetic and plant-growth-promoting characteristics of Bacillus isolated from the wheat rhizosphere. Ann Microbiol. 2016;66(3):1087-1097. doi: 10.1007/s13213-016-1194-6

43. Rashid U, Yasmin H, Hassan MN, et al. Droughttolerant Bacillus megaterium isolated from semi-arid conditions induces systemic tolerance of wheat under drought conditions. Plant Cell Report. 2021. doi: 10.1007/s00299-020-02640-x

44. Bákonyi N, Gajdos É, Lévai L, Veres S, Tóth B, Marozsán $M$. Comparison of effects of different biofertilisers on early development of cucumber and wheat seedlings. Ratarstvo. 2009;44:491-495.

45. Vardharajula S, Ali SkZ, Grover M, Reddy G, Venkateswarlu B. Drought-tolerant plant growth promoting Bacillus spp., effect on growth, osmolytes, and antioxidant status of maize under drought stress. J Plant Inter. 2011;6:1-14. doi: 10.1080/17429145.2010.535178

46. Moreno-Galvan A, Romero-Perdomo FA, EstradaBonilla G, Meneses CHSG, Bonilla RR. Dry-Caribbean Bacillus spp. strains ameliorate drought stress in maize by a strain-specific antioxidant response modulation. Microorganisms. 2020;8(6):823. doi: 10.3390/ microorganisms 8060823

47. Egamberdieva D, Wirth SJ, Shurigin VV, Hashem A, Abd_Allah EF. Endophytic bacteria improve plant growth, symbiotic performance of chickpea (Cicer arietinum $\mathrm{L}$.) and induce suppression of root rot caused by Fusarium solani under salt stress. Front Microbiol. 2017:8:1887. doi: 10.3389/fmicb.2017.01887.

48. Hashem A, Tabassum B, Abd_Allah EF. Bacillus subtilis
: A plant-growth promoting rhizobacterium that also impacts biotic stress. Saudi J Biol Sci. 2019;26(6):12911297. doi: 10.1016/j.sjbs.2019.05.004

49. Sandhya V, Ali SZ, Grover, M, Reddy G, Venkateswarlu B. Effect of plant growth promoting Pseudomonas spp. on compatible solutes, antioxidant status and plant growth of maize under drought stress. Plant Growth Regul. 2010;62(1):21-30. doi: 10.1007/s10725-0109479-4

50. Ahemad M, Kibret M. Mechanisms and applications of plant growth promoting rhizobacteria: Current perspective. J King Saud Uni Sci. 2014;26:1-20. doi: 10.1016/j.jksus.2013.05.001

51. Viscardi S, Ventorino V, Duran P, et al. Assessment of plant growth promoting activities and abiotic stress tolerance of Azotobacter chroococcum strains for a potential use in sustainable agriculture. J Soil Sci Plant Nut. 2016;16(3):848-863. doi: 10.4067/S071895162016005000060

52. Devarajan AK, Muthukrishanan G, Truu J, et al. The foliar application of rice phyllosphere bacteria induces drought-stress tolerance in Oryza sativa (L.). Plants. 2021;10(2):387. doi: 10.3390/plants10020387

53. Sunar K. Studies on soil microbial diversity of Darjeeling hills and their evaluation for utilization in the improvement of crop health, Doctoral dissertation, University of North Bengal. 2013.

54. Batool T, Ali S, Seleiman MF, et al. Plant growth promoting rhizobacteria alleviates drought stress in potato in response to suppressive oxidative stress and antioxidant enzymes activities. Sci Rep. 2020;10(1):16975. doi: 10.1038/s41598-020-73489-z

55. Fotovat $\mathrm{R}$, Valizadeh $\mathrm{M}$, Toorchi M. Association between water-use efficiency components and total chlorophyll content (SPAD) in wheat (Triticum aestivum L.) under well-watered and drought stress conditions. $J$ Food Agric Environ. 2007;5(3-4):225-227.

56. Keyvan $\mathrm{S}$. The effects of drought stress on yield, relative water content, proline, soluble carbohydrates and chlorophyll of bread wheat cultivars. J Anim Plant Sci. 2010;8:1051-1060.

57. Abd El-Daim IA, Bejai S, Meijer J. Bacillus velezensis 5113 induced metabolic and molecular reprogramming during abiotic stress tolerance in wheat. Sci Rep. 2019;9:16282. doi: 10.1038/s41598-019-52567-x

58. Kasim WA, Osman ME, Omar MN, Abd El-Daim IA, Bejai S, Meijer J. Control of drought stress in wheat using plant-growth-promoting bacteria.J Plant Growth Regul. 2013;32:122-130. doi: 10.1007/s00344-0129283-7 